

\title{
Crianças em situação de rua e suas representações sobre lar e família por meio do desenho
}

\author{
Street children and their representations of home and family through drawing
}

Josianne Maria Mattos da Silva ${ }^{[a]}$, Telma Costa de Avelar ${ }^{[b]}$

\begin{abstract}
${ }^{a]}$ Psicóloga graduada em Psicologia pela Universidade Federal de Pernambuco (UFPE), Especialista em Residência Multiprofissional Integrada em Saúde pelo Hospita das Clínicas da UFPE, Recife, PE Brasil, e-mail:

josiannemattos@hotmail.com

${ }^{[b]}$ Psicóloga, mestre em Psicologia Cognitiva, professora assistente da Universidade Federal de Pernambuco (UFPE), Recife, PE Brasil, e-mail:

telma_avelar@yahoo.com.br
\end{abstract}

Recebido: 07/10/2011 Received: 10/07/2011

Aprovado: $15 / 11 / 2012$ Approved: 11/15/2012

\section{Resumo}

Para crianças em situação de rua, este espaço representa um ambiente de socialização e trabalho. Alguns autores salientam que o contexto familiar destas crianças favorece a saída de suas casas. A vulnerabilidade tornou-se um aspecto importante a ser considerado na compreensão de seus vínculos familiares. 0 presente estudo, de abordagem qualitativo-exploratória, consistiu em investigar as representações de crianças em situação de rua sobre seus lares e famílias mediante a linguagem simbólica do desenho. Participaram dele sete crianças em situação de rua, de ambos os sexos, com idades entre dez e quatorze anos. Foram aplicados dois instrumentos projetivos: o teste do desenho da família e o protocolo para o desenho da casa, referente ao teste House-Tree-Person (HTP). Os resultados apontaram que, para os participantes, o modelo de família não equivale ao modelo nuclear. Apontaram ainda mobilização diante dos desenhos, ambivalência afetiva em relação ao lar e à família e fragilidade nos laços afetivos. Pôde-se inferir que a ida das crianças à rua está relacionada a questões financeiras e afetivas, e que alguns destes aspectos ainda se preservam com a vivência nas ruas.

Palavras-chave: Criança abandonada. Família. Lar. Desenho.

\begin{abstract}
For street children, the streets represent a place of socialization and work. Many authors believe that the dynamic of their family determines the decision of leaving home. The vulnerability has become an important aspect to be considered in relation to the comprehension of their family bonds. This paper (based on an exploratory/qualitative approach) aims to investigate the street children's representation of their homes and families through the symbolic language of the drawing. Seven street children participated, from both sexes, aging ten to fourteen. Two projective assessment techniques were used: the family drawing test and the house drawing protocol, from the House-Tree-Person (HTP) test. The results showed that, for the participants, the model of family is not the nuclear family model. It also presented children's sensitivity, affective ambivalence related to home and family, and a frailty of affectional bonds. It was possible to understand that the fact of children leaving their homes is related to affectional and monetary issues, and that some of these aspects are still preserved in the life on the streets.
\end{abstract}

Keywords: Child, Abandoned. Family. Home. Drawing.

Psicol. Argum. 2014 jan./mar., 32(76), 69-77 


\section{Introdução}

Este estudo, baseado na abordagem qualitativo-exploratória, buscou compreender o contexto e as relações familiares de crianças em situação de rua, entendendo este espaço não somente como um lugar de passagem, podendo significar também um lugar onde se formam vínculos.

Sobre os vínculos familiares, Neiva-Silva (2003) refere que estes sempre foram considerados como um dos fatores mais relevantes na descrição de crianças em situação de rua. Associados a outros fatores - como expectativas futuras em relação ao trabalho, educação e moradia -, relacionam-se ao processo de construção e desconstrução de projetos de vida.

Segundo Gomes e Pereira (2005), uma das provas mais evidentes da existência de uma família é o viver sob o mesmo teto, ou seja, a casa em que habitam. Segundo as autoras, a noção de casa remete a uma determinada maneira de vida chamada de convivência familiar. Para Sarti (citado por Gomes \& Pereira, 2005, p. 358), "a família compreende a casa; a casa está, portanto, contida na família". Assim, as concepções de casa e família estão imbricadas até mesmo no imaginário popular, sendo a casa o lugar onde as dinâmicas familiares se processam.

A partir da relação casa-família, surgiu em nossa pesquisa o questionamento sobre como crianças em situação de rua representariam suas casas e como estas e suas famílias se manifestariam num discurso não verbal. A relevância deste estudo está na compreensão acerca do universo familiar destas crianças e na possibilidade da intervenção neste contexto a partir de suas representações.

Para responder esta indagação utilizou-se a linguagem simbólica do desenho, com o intuito de compreender como se dá a dinâmica destas representações. 0 desenho foi escolhido como instrumento desta pesquisa pelo fato de ser considerado por diversos autores (Hammer, 1981; Winnicott, 1984; Goldberg, Yunes \& Freitas, 2005) como uma ferramenta com a qual a criança consegue expressar aquilo que não consegue dizer por meio da fala, o que possibilita que entrem em contato com seu universo interior e assim possam representá-lo.

\section{Considerações sobre o contexto familiar de crianças em situaç̃̃o de rua}

Conforme citado por Sales, Matos e Leal (2006), a família, apesar de defendida como base da sociedade, tem sido sujeitada à pauperização e diminuição da qualidade de vida de seus integrantes. Para Sarmento (2002), de maneira progressiva, ela perde o significado da primeira instância de socialização, como causa das sucessivas recomposições e reestruturações que tem sofrido. Este estatuto tende a deslocar-se para o espaço público, seja ele o das instituições estatais, seja o da rua ou o do bairro; espaços estes geradores de novos processos de referência e sociabilidades nas novas gerações.

Para Gregori (2000), faz-se comumente uma relação entre a organização - ou desestruturação - familiar e a saída da criança de sua casa. Essa concepção se apoia no modelo ideal de família ou família nuclear completa (pai, mãe, filhos, sendo o pai o principal provedor). Embora as diferentes configurações familiares não determinem a situação futura dos meninos de rua, elas são essenciais para o entendimento do sujeito e sua escolha de viver na rua, ainda que a escolha seja forçada. Paludo e Koller (2008) acrescentam que a rua é uma consequência da má resolução dos conflitos emergentes no ambiente familiar. No entanto, no caso de famílias de crianças e adolescentes em situação de rua, os infortúnios vivenciados não significam, obrigatoriamente, sua desconfiguração como família.

Numa tentativa de caracterizar a família dos meninos de rua, Ferreira (2001) diz que o grupo familiar destas crianças, frequentemente, circunda a mãe, sendo ela a figura mais presente; ao contrário do pai, muitas vezes alcoolista, desempregado ou mesmo desconhecido. Nestas condições, a contribuição financeira dos filhos, somada à da mãe, é essencial, e, às vezes, substitui ou supera a do pai. Ferreira (1980) acrescenta que este compromisso de levar dinheiro para casa além de fazer que os laços familiares não sejam rompidos totalmente, faz que a criança acabe sendo obrigada a garantir também sua própria sobrevivência, tendo que conseguir o que comer e vestir, além de um lugar onde dormir.

Paludo e Koller (2008) comentam que essas famílias precisam desenvolver estratégias de 
sobrevivência, sejam estas econômicas e/ou afetivas. Toda a rede familiar precisa contribuir com a manutenção do lar. Diante disto, muitas vezes, a saída para a rua acaba sendo um meio para alcançar este objetivo e os meninos fazem da rua sua casa, criando uma nova topologia; com isto "[...] o bando vai, pouco a pouco, substituindo o grupo familiar. Os laços com a família, se os meninos conseguem mantê-los, são enfraquecidos e, para muitos, inexistentes. A rua vai fazendo seu desenlace" (Gregori, 2000, p. 89).

\section{0 conceito de projeção e o desenho como instrumento projetivo}

No sentido psicanalítico, define-se projeção como "operação pela qual o sujeito expulsa de si e localiza no outro - pessoa ou coisa - qualidades, sentimentos, desejos e mesmo 'objetos' que ele desconhece ou recusa nele" (Laplanche, 2001, p. 374).

Ao conceito de projeção, Hammer (1981) acrescenta a ideia de este se tratar de um fenômeno que deve ser visto não somente como projeção de algo recalcado, e o define como uma forma de se colocar a experiência interna no mundo exterior, como um processo psicológico no qual as pessoas atribuem qualidades e sentimentos aos objetos do ambiente - entendendo-se por objeto as pessoas, organismos ou coisas -, sendo este conteúdo projetivo reconhecido ou não pelo sujeito como algo dele.

Sobre o desenho como instrumento projetivo, há muito tempo os seres humanos utilizam-no como forma de representar pensamentos, sentimentos e ações. 0 homem primitivo já fazia uso da linguagem simbólica do desenho, empregando-o antes mesmo dos símbolos que registrassem especificamente a sua fala. Este simbolismo do desenho permite a comunicação desde épocas bastante precoces da vida do ser humano, possibilitando a capacidade de expressão desde a infância, antes mesmo de aprender a escrever (Hammer, 1981). Desta maneira, o desenho infantil constitui-se como uma das primeiras formas de expressão, surgindo antes do desenvolvimento da leitura e da escrita.

Para Mèredieu (1999), o desenho infantil é como uma língua com seu próprio vocabulário e sintaxe. Hammer (1981), por sua vez, ressalta que, ao desenhar, as crianças transmitem coisas que não conseguiriam expressar por palavras, mesmo que estivessem conscientes dos sentimentos que as mobilizam.

Do mesmo modo, Rocha (1970) coloca que, com o desenho espontâneo, a criança cria uma estrutura que a leva com maior facilidade em direção às suas emoções, fantasias e sentimentos. Segundo o autor, "o desenho proporciona ao menor a oportunidade de estabelecer conexões associativas entre as suas fantasias e o material projetivo, o que nos possibilita uma investigação mais acurada de seu psiquismo" (Rocha, 1970, p. 31).

As técnicas projetivas são utilizadas em contextos diversos e a maneira como o sujeito interpreta o teste e responde a ele reflete aspectos fundamentais de seu funcionamento psíquico (Silva \& VillemorAmaral, 2006). Para Campos (2006), o uso do desenho como técnica projetiva favorece o surgimento dos conflitos mais profundos, pois estes se refletem melhor na folha de papel. Diante disto, o desenho se revela como uma técnica que permite explorar, por assim dizer, a realidade interna do indivíduo (Siqueira, Doro \& Santos, 2003). Uma vez que é na folha em branco que o sujeito deve criar formas e sentido, ele irá vivenciar uma situação emocional intensa, pois vai construir o que lhe foi pedido buscando significados internos que resultarão numa resposta gráfica.

Segundo Campos (2006), o desenho da casa é um retrato no qual se encontram fantasia, ego e realidade, e que expressa a percepção da situação lar-residência, tanto no presente quanto em relação às expectativas futuras. Já o desenho da família permite que se conheça a situação do indivíduo dentro de seu ambiente familiar.

\section{Método}

Participantes

Participaram desta pesquisa sete crianças em situação de rua, assistidas por uma Organização não Governamental (ONG) na cidade do Recife, Pernambuco. Elas foram incluídas nos seguintes critérios: ambos os sexos, faixa etária entre dez e quatorze anos de idade. Parte dos desenhos foi feita na cidade do Recife em companhia de educadores da ONG; a coleta ocorreu enquanto as crianças estavam na rua. A outra parte da coleta foi realizada

Psicol. Argum. 2014 jan./mar., 32(76), 69-77 
num sítio da ONG localizado no estado da Paraíba, local destinado a acolher crianças e adolescentes que desejam sair da situação de rua.

\section{Instrumentos}

Foram utilizados dois instrumentos caracterizados como técnicas projetivas: o teste HTP (Buck, 2003) e o teste do desenho da família (Corman, 2003). O House-True-Person (HTP), ou teste da casa-árvore-pessoa, é uma técnica projetiva que permite ao psicólogo estabelecer hipóteses dinâmicas e estruturais sobre o indivíduo. 0 conteúdo do desenho realizado pelo sujeito permite averiguar a percepção consciente e inconsciente em relação a si próprio e ainda em relação às figuras significativas de seu ambiente (Retondo, 2000). 0 teste é composto pelos protocolos dos desenhos da casa, da árvore e da pessoa, os quais podem ser utilizados de maneira combinada ou separadamente. Este trabalho utilizou somente o protocolo do desenho da casa.

0 HTP foi utilizado para investigar a representação dos participantes acerca de seus lares. Para sua aplicação foram necessários: lápis preto número 2 , protocolo para o desenho da casa (folha de papel A4) e caixa de lápis colorido. As instruções foram: "Eu quero que você desenhe uma casa. Você pode desenhar o tipo de casa que quiser. Faça o melhor que puder. Você pode apagar o quanto quiser e pode levar o tempo que precisar. Apenas faça o melhor possível." (Buck, 2003, p. 6). Também foi solicitado que utilizassem o lápis de colorir. Ao final do desenho foi feito inquérito visando à expressão de ideias, pensamentos e sentimentos, o que permitiu que o sujeito definisse, descrevesse e interpretasse seu desenho. Tal inquérito incluía perguntas como: "De que esta casa é feita? Esta é sua própria casa? Quem você gostaria que morasse nesta casa com você e por quê? É um tipo de casa feliz, amigável?".

Já o desenho da família foi empregado para compreender a representação que tem para a criança. A instrução fornecida foi: "Desenhe uma família" ou "desenhe uma família qualquer". Após o desenho, seguiu-se um inquérito em que os personagens foram identificados e alguns aspectos esclarecidos, como: "Qual o melhor? Qual o pior? Qual o mais feliz? E você, nesta família, quem prefere? Qual deles gostaria de ser?". Para cada resposta dada procurou-se saber o porquê. 0 material utilizado para aplicação do desenho da família foi o mesmo utilizado para o HTP. A análise foi baseada nos aspectos referidos por Ramalho (2008), que, por sua vez, foram baseados em Hammer (1981) e Corman (2003).

\section{Procedimentos}

Esta pesquisa foi desenvolvida de acordo com a Resolução $n$ o 196 de 10 de outubro de 1996, que dispõe sobre as Diretrizes e Normas Regulamentadoras de Pesquisas Envolvendo Seres Humanos (Brasil, 1996). Iniciou-se após a aprovação do Comitê de Ética em Pesquisa (CEP) da Universidade Federal de Pernambuco (UFPE), onde está registrada com o número 400/08. A pesquisa de campo, a análise dos dados e a conclusão da pesquisa ocorreram entre fevereiro e junho de 2009.

Inicialmente entrou-se em contato com a ONG visando sua colaboração com a pesquisa, a mediação do contato com as crianças e o fornecimento de informações sobre elas. Nas instruções, primeiro lhes foi solicitado que fizessem o desenho da casa, o qual foi seguido de inquérito. Em seguida, foi solicitado que desenhassem uma família e respondessem, ao término do desenho, perguntas referentes ao material produzido. A análise dos desenhos considerou, além do inquérito, aspectos como tempo de latência, perspectiva, proporção, detalhes, qualidade da linha, uso de cores e observações gerais que incluem comentários espontâneos, rasuras e pausas. As folhas para a realização de ambos os desenhos foram apresentadas aos participantes na posição horizontal, conforme a sugestão dos protocolos para aplicação. A análise qualitativa dos dados ocorreu a partir de informações dadas pelos educadores sociais sobre o contexto das crianças, associadas aos desenhos produzidos e aos relatos dos participantes.

\section{Resultados e discussões}

Os desenhos a seguir são de um dos participantes da pesquisa e exemplificam como as análises foram feitas. Trata-se dos desenhos de Luiz (nome fictício, assim como os nomes atribuídos aos demais participantes da pesquisa), garoto de quatorze anos, em cuja casa vivem seus irmãos, sua mãe e seu padrasto. 0 pai de Luiz já faleceu. A mãe e seu companheiro têm uma relação bastante conturbada, permeada 
por muitas discussões. Além disso, são usuários de álcool e outras substâncias psicoativas. Segundo relato dos educadores, a mãe não se importa com a situação dos filhos e isto é percebido por eles. Apesar disso, são bastante apegados a ela e não permitem que ninguém fale mal a seu respeito. $\mathrm{Na}$ tentativa de ocultar a realidade, a mãe não concorda que sejam feitas visitas domiciliares pela ONG à sua casa, recebe-os por uma pequena abertura na porta, por onde conversam. Sua mãe também não participa das reuniões de grupo proporcionadas pela ONG que pretendem fazer articulações entre as crianças e as famílias, além de encaminhamentos pertinentes ao contexto socioeconômico.

Luiz vive no sítio há cerca de três anos. Ele retorna ao convívio familiar nos fins de semana. Passou a viver nas ruas em busca de dinheiro. Seu irmão mais velho também vive no sítio e foi por intermédio dele que Luiz passou a frequentar o local. Segundo uma das educadoras, Luiz é uma criança muito tímida e está sempre cabisbaixo, parece ter vergonha de olhar nos olhos dos outros. É também muito ingênuo e precisa de cuidados especiais por causa disso.

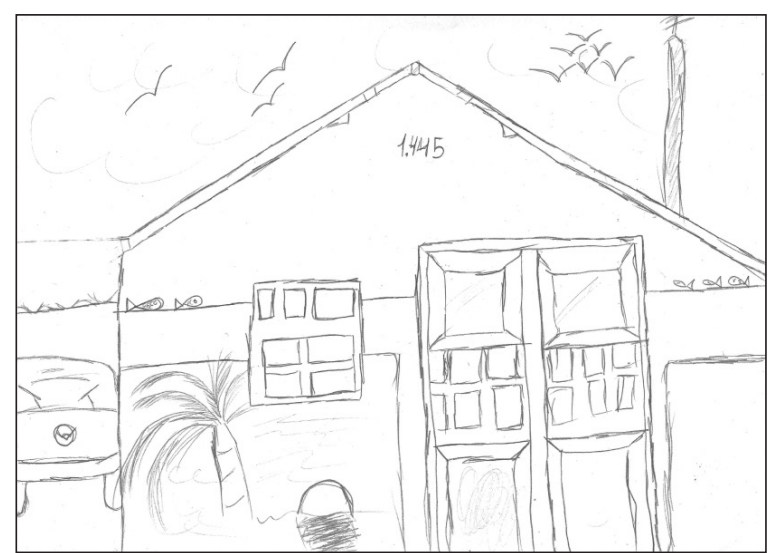

Figura 1 - Desenho da casa feito por Luiz

O desenho teve tempo de latência de oito segundos e tempo total de vinte minutos. Segundo informações obtidas a partir do inquérito, Luiz relata que a casa possui um andar e é feita de tijolos (orientação para a realidade). Ele diz ter desenhado sua própria casa e que estava pensando nela no momento do desenho. Não gostaria que a casa fosse sua, e justificou da seguinte forma: "não quero voltar pra lá porque já vi muita morte". Gostaria que morassem na casa, além dele, o irmão, as duas irmãs e a mãe. Quando a examinadora pergunta com quem mora, ele responde que vive com o irmão e as duas irmãs, excluindo a mãe e seu companheiro. Sobre o que a casa o faz lembrar responde: "do passado, quando eu vivia na rua”. A casa lembra também de seu pai que já faleceu. É um tipo de casa feliz "porque é grande". Sobre o que a casa mais precisa, ele responde: "De gente. Porque se não tiver gente na casa, a casa não vai valer".

O desenhoé degrande dimensão. Para Buck(2003), um desenho com estas características de dimensão e é cortado pelo papel, geralmente indica sentimento de irritabilidade em relação a um ambiente restritivo. A linha forte indica tensão, ansiedade, energia e organicidade, e apresenta traço de avanços e recuos que indicam ansiedade, emotividade, falta de confiança, timidez, insegurança, intuição e sensibilidade.

Durante o desenho, ele nada comenta, mas há um comentário escrito (número da casa), o que representa a necessidade de estruturar a situação da forma mais completa possível. Os detalhes do desenho (carro, pássaros, nuvem, peixes etc.) indicam insegurança, ansiedade ou necessidade de estruturar a situação de forma mais segura. A porta é grande, sugerindo dependência.

Quando foi solicitado para que falasse sobre a casa desenhada e as pessoas que viviam nela, ele se recusou. Mas relata não querer voltar para sua casa; no entanto, gostaria que a família morasse lá com ele e o irmão. Também se recusou a colorir o desenho, o que insinua comprometimento da afetividade dirigida às questões do lar.

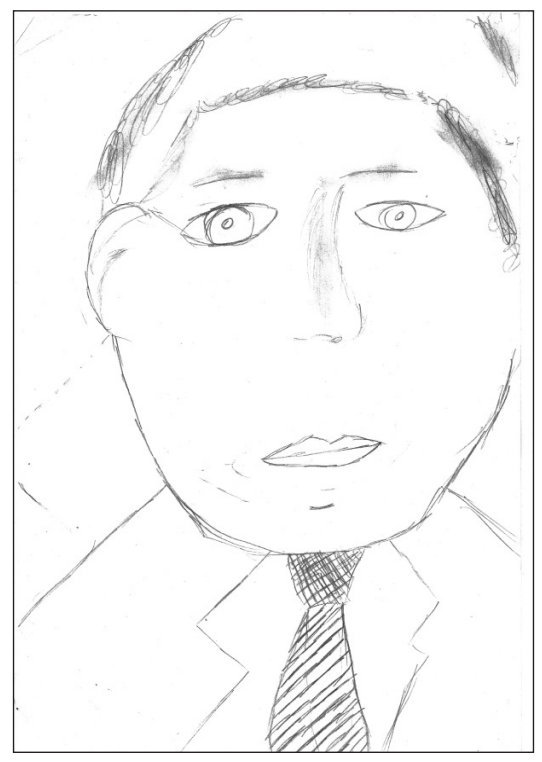

Figura 2 - Desenho da família feito por Luiz

Psicol. Argum. 2014 jan./mar., 32(76), 69-77 
Quando o desenho da família é solicitado, Luiz pergunta: "Posso desenhar só o meu pai?". A examinadora responde que ele pode desenhar quem quiser. Como há somente uma figura no desenho, as perguntas do questionário foram dispensadas, visto que são perguntas comparativas.

Quanto aos aspectos gerais e formais, o desenho tem tamanho demasiadamente grande, ocupando toda a folha, saindo do papel, o que sugere sentimento de constrição por parte do ambiente, com fantasia supercompensatória. 0 traçado é interrompido indicando incerteza, temor e angústia; e o traço é forte indicando audácia, violência, liberação instintiva e impulsos fortes. Faz uso da borracha diversas vezes, o que indica conflito com a figura desenhada, bem como insatisfação com o desenho.

Em relação ao conteúdo, Luiz desenha unicamente seu pai que já faleceu há cerca de dois anos. Segundo ele, "quando meu pai era vivo tinha comida em casa". A examinadora pergunta se não há mais comida em sua casa e ele responde: "Agora ainda tem mais é menos". Disse ainda que viu seu pai morrer e que se lembra de quando ele era vivo e acordava cedo e fazia o café, saindo depois para trabalhar. Luiz disse ter visto o pai morrer. Conta que estava na rua e foram lhe chamar porque seu pai estava passando mal; quando chegou em casa estava morrendo.

No desenho há omissão da mãe, indicando conflito e problemas de relacionamento. Omite ainda os irmãos, o que revelaria rivalidade fraterna; além disso, ele também é excluído do desenho, indicando desejo de não pertencimento à família, exclusão e desvalorização. Há ainda sombreamento, um indicador de conflito emocional, ansiedade e angústia.

\section{Síntese interpretativa dos desenhos de Luiz}

Durante a execução dos dois desenhos Luiz se comportou de maneira tímida e retraída, sempre cabisbaixo e calado. Conforme citado por uma das educadoras da ONG, ele procurava sempre desviar o olhar enquanto falava com a examinadora.

A referência de família para Luiz parece ser o pai que já faleceu, visto que preferiu desenhar somente sua figura. Nesta época as relações familiares eram mais estáveis e as dificuldades financeiras mais brandas. Ele não citou a mãe em nenhum momento, bem como os outros irmãos; referiu-se somente ao irmão mais velho que também mora no sítio. No entanto, a desvalorização de sua família sugerida no desenho não é congruente com a fala de Luiz que relata seu desejo de que a família morasse no sítio com ele. Porém, parece haver ambivalência afetiva em relação à mãe, pois Luiz faz referência somente ao fato de seus irmãos viverem na casa - excluindo a mãe -, mas demonstra o desejo de vê-la vivendo no sítio com o resto da família. A figura do padrasto não surge em nenhum momento, nem na fala de Luiz nem em seu desenho.

As informações sobre a família de Luiz insinuam uma dinâmica familiar de caráter agressivo, permeada por confusões causadas pela mãe e seu companheiro, as quais acabam mobilizando a família, o que pode contribuir para a falta de investimento afetivo em relação ao lar, sinalizado pela ausência de cores no desenho da casa.

Observa-se que, das sete crianças, somente duas apresentaram resistência em desenhar a casa; cinco crianças desenharam suas próprias casas, e duas retrataram o sítio onde estão vivendo atualmente, demonstrando que a referência de lar pode mudar depois da inserção em um novo modelo. Seis crianças fizeram uso de "detalhes irrelevantes" no desenho (como nuvens e pássaros), o que indica, segundo Buck (2003), necessidade de afastamento do tema principal, algo enfatizado pelas seis crianças que apresentaram algum tipo de resistência ao inquérito - seja não respondendo, seja querendo afastar-se do exame -, e que sinaliza dificuldade de entrar em contato com as associações despertadas pelo inquérito.

Quatro crianças fizeram uso de cor no desenho e três não, o que, no último caso, pode ser entendido como falta de investimento afetivo em relação ao lar, ou ainda uma tentativa de fugir ou de se proteger dos sentimentos que a cor evoca. Para quatro crianças, a casa parece perto, característica que está relacionada ao fato de ainda existirem sentimentos de acolhimento e calor ou a capacidade de realização em relação ao lar. Todas as crianças incluem pessoas de sua família na casa quando questionadas sobre quais pessoas gostariam que morassem nela, demonstrando que ainda há desejo de compartilhar o lar com pessoas da família.

Os resultados do desenho da casa apontaram uma ambivalência afetiva no que diz respeito aos sentimentos despertados pelo lar, pois revelaram representações tanto positivas quanto negativas. 
Tabela 1 - Síntese das respostas obtidas no desenho da casa

\begin{tabular}{lccccccc}
\hline Respostas & $\begin{array}{c}\text { Resistência } \\
\text { em desenhar }\end{array}$ & $\begin{array}{c}\text { Desenha } \\
\text { sua própria } \\
\text { casa }\end{array}$ & $\begin{array}{c}\text { Uso de detalhes } \\
\text { "irrelevantes" }\end{array}$ & $\begin{array}{c}\text { Uso } \\
\text { de } \\
\text { cores }\end{array}$ & $\begin{array}{c}\text { Distância } \\
\text { da casa }\end{array}$ & $\begin{array}{c}\text { Quem } \\
\text { gostaria que } \\
\text { morasse na } \\
\text { casa }\end{array}$ & $\begin{array}{c}\text { Resistência } \\
\text { em responder } \\
\text { ao inquérito }\end{array}$ \\
\hline Leandro & Não & Não & Sim & Sim & Perto & Família & Sim \\
Thiago & Não & Não & Não & Sim & Perto & Família + & Leandro \\
Luiz & Não & Sim & Sim & Não & Longe & Família & Sim \\
Tayná & Não & Sim & Sim & Sim & Não responde & Família & Sim \\
Diego & Não & Sim & Sim & Não & Perto & O pai & Sim \\
Eduardo & Sim & Sim & Sim & Não & Perto & A mãe & Sim \\
Giovane & Sim & Sim & Sim & Sim & Longe & Família & Não \\
\hline
\end{tabular}

Na Tabela 2 observa-se que das sete crianças que participaram da pesquisa três apresentaram resistência em desenhá-la e duas se recusaram a fazê-lo. De acordo com Di Leo (1991), em relação às crianças que possuem imagem negativa da família e que a vida no lar é permeada por tumulto e violência, é comum haver resistência ou negação em desenhar a família. Para o autor, mesmo diante disso, é rara a recusa absoluta em desenhar; de maneira geral, eles retratam a família incluindo si mesmos e os irmãos, excluindo a figura dos pais. Esta resistência ou negação em desenhar a família, bem como a omissão das figuras dos pais pode ser observada na Tabela 2, que revela que, das cinco crianças que desenharam a família, duas não apresentaram pai e mãe, uma não representou o pai e outra não representou a mãe.

A Tabela 2 ainda demonstra que todas as crianças desenharam uma família ideal, caracterizada pelo acréscimo ou eliminação de figuras - duas crianças fizeram acréscimo de outras pessoas no desenho e quatro fizeram eliminação. Surgem assim seus próprios modelos familiares que vão além do modelo de família nuclear.

Das cinco crianças que desenharam a família, duas apresentaram dificuldade em se inserir no desenho, evidenciando dificuldade de pertencer à família (Corman, 2003; Ramalho, 2008), e três apresentaram distância entre as figuras desenhadas, o que evidencia a percepção das crianças em relação aos laços afetivos.

Comparando-se as Tabelas 1 e 2, pode-se verificar que um número maior de crianças apresentou resistência - havendo inclusive recusa - em desenhar a família. Possivelmente este desenho é mais mobilizador no que diz respeito às relações familiares, despertando associações que trazem à tona aspectos mais difíceis de serem retratados.

No tocante às reações das crianças perante os desenhos, Buck (2003, p. 23) salienta que "a atitude em cada desenho será influenciada pelas associações despertadas pelo objeto desenhado". Provavelmente, as representações dessas crianças sobre lar e família tornaram, em alguns casos, difíceis as produções dos desenhos, já que enquanto desenham elas falam de si.

Ao analisar os desenhos foi possível perceber fragilidade nos laços afetivos - decorrentes de problemas familiares -, o que pôde ser verificado nos desenhos das crianças, quando estes apresentaram distanciamento entre as figuras. No entanto, apesar da afetividade fragilizada, ainda se nota a preservação de laços afetivos - por exemplo: das três crianças que participaram da pesquisa e que estavam no processo de moradia no sítio, todas afirmaram que não queriam sair de lá, mas que gostariam que seus familiares fossem viver com eles. Isso demonstra que, embora haja desarmonia no lar, ainda há afetividade direcionada às suas famílias, uma preocupação em relação à situação em que a família se encontra e também há o desejo de compartilhar um lar - talvez este seja representado negativamente, 0 que também contribui para que as crianças queiram mudar de suas casas -, mas um lar de outra espécie, onde uma nova referência de família também possa ser construída.

Psicol. Argum. 2014 jan./mar., 32(76), 69-77 
Tabela 2 - Sintese das respostas obtidas no desenho da familia

\begin{tabular}{|c|c|c|c|c|c|c|c|}
\hline Respostas & $\begin{array}{l}\text { Resistência } \\
\text { em desenhar } \\
\text { a família }\end{array}$ & $\begin{array}{c}\text { Dificuldade } \\
\text { em se inserir } \\
\text { no desenho }\end{array}$ & $\begin{array}{c}\text { Distância } \\
\text { entre as } \\
\text { figuras }\end{array}$ & $\begin{array}{c}\text { Não } \\
\text { representa } \\
\text { o pai }\end{array}$ & $\begin{array}{l}\text { Não } \\
\text { representa } \\
\text { a mãe }\end{array}$ & $\begin{array}{c}\text { Acréscimo } \\
\text { de outras } \\
\text { pessoas }\end{array}$ & $\begin{array}{c}\text { Eliminação } \\
\text { de figuras }\end{array}$ \\
\hline Leandro & Não & Não & Sim & Sim & Sim & Sim & Sim \\
\hline Thiago & Não & Não & Sim & Não & Não & Sim & Não \\
\hline Luiz & Sim & Sim & $\begin{array}{l}\text { Figura } \\
\text { única }\end{array}$ & Não & Sim & Não & Sim \\
\hline Tayná & Sim & Sim & Sim & Sim & Sim & Não & Sim \\
\hline Diego & Recusa & - & - & - & - & - & - \\
\hline Eduardo & Recusa & - & - & - & - & - & - \\
\hline Giovane & Sim & Não & Não & Sim & Não & Não & Sim \\
\hline
\end{tabular}

Foi possível observar também que as representações das crianças estão alicerçadas num modelo ideal de família, visto que seus desenhos não refletiram suas famílias reais. Também foi possível verificar muitos indicadores de conflito, bem como sinais de sentimentos negativos, como insegurança, irritabilidade medo e ansiedade. Durante a pesquisa ainda foi possível perceber sentimentos de mobilização diante dos desenhos, o que acarretou em alguns comportamentos das crianças, como a recusa ou resistência em desenhar, e até em responder ao inquérito.

\section{Considerações finais}

Neste estudo foi possível verificar que as crianças em situação de rua possuem representações ambivalentes a respeito de suas famílias, ocorrendo o mesmo em relação à representação de seus lares. Esta emergência de sentimentos decorrentes da relação lar e família pode ser percebida, por exemplo, com o afastamento entre os membros da família em alguns desenhos, juntamente com o não uso de cores nos desenhos da família e/ou da casa e a eliminação de figuras representativas, como a mãe. No entanto, apesar destas representações, ainda surge na fala das crianças o desejo de viver com a família na casa desenhada por elas.

Gomes (citado por Gomes \& Pereira 2005, p. 359) comenta que "quando a casa deixa de ser um espaço de proteção para ser um espaço de conflito, a superação desta situação se dá de forma muito fragmentada, uma vez que esta família não dispõe de rede de apoio para o enfrentamento das adversidades". Diante disto, pode-se dizer que construir um trabalho com crianças e adolescentes em situação de rua, requer a inserção delas numa rede de apoio social para que possam se desenvolver em ambientes protetivos que resgatem sua afetividade e onde tenham seus direitos preservados.

\section{Referências}

Brasil. Ministério da Saúde. Conselho Nacional de Saúde. Resolução no 196/96 (1996). Diretrizes e normas regulamentadoras de pesquisas envolvendo seres humanos. Diário Oficial da República Federativa do Brasil.

Buck, J. (2003). H - T - P: casa-árvore-pessoa, técnica projetiva de desenho: manual e guia de interpretação (R. Cury, Trad.). São Paulo: Vetor.

Campos, D. M. S. (2006). O teste do desenho como instrumento de diagnóstico da personalidade: validade, técnica de aplicação e normas de interpretação (38aㅡ. ed.). Petrópolis: Vozes, 2006.

Corman, L. (2003). O teste do desenho da família (W. Geenen, Trad.). São Paulo: Mestre Jou.

Di Leo, J. H. (1991). A interpretação do desenho infantil (3 $3^{\text {a }}$ ed.). Porto Alegre: Artes Médicas, 1991.

Ferreira, R. M. F. (1980). Meninos da Rua: expectativas e valores de menores marginalizados em São Paulo. São Paulo: Ibrex. 
Ferreira, T. (2001). Os meninos e a rua: uma interpretação à psicanálise. Belo Horizonte: Autêntica/FUMEC.

Goldberg, L. G., Yunes, M. A. M., \& Freitas, J. V. (2005). 0 desenho infantil na ótica da ecologia do desenvolvimento humano. Psicologia em estudo, 10(1), 97-106. Recuperado em 28 set. 2008, de http://www.scielo.br/scielo.php?script=sci_ arttext\&pid=S1413-73722005000100012\&lng=pt $\& n r m=i s o$

Gomes, M., \& Pereira, M. (2005). Famílias em situação de vulnerabilidade social: Uma questão de políticas públicas. Ciência \& Saúde Coletiva, 2, 357-363.

Gregori, M. F. (2000). Desenhos familiares: pesquisa sobre família de crianças e adolescentes em situação de rua. São Paulo: Allegro.

Hammer, E. F. (1981). Aplicações clínicas dos desenhos projetivos (E. Nick, Trad.). Rio de Janeiro: Interamericana.

Laplanche, J. (2001). Vocabulário de psicanálise Laplanche e Pontalis ( $4^{\mathrm{a}}$ ed.). (P. Tamen, Trad.). São Paulo: Martins Fontes.

Mèredieu, F. (1999). O desenho infantil ( $6^{\mathrm{a}}$ ed.). (A. Lorencini, Trad.). São Paulo: Cultrix.

Neiva-Silva, L. (2003). Expectativas futuras de crianças e adolescentes em situação de rua: um estudo autofotográfico. Dissertação de Mestrado em Psicologia, Universidade Federal do Rio Grande do Sul, Porto Alegre. Recuperado em 26 out. 2008, de http://www. msmidia.com/ceprua/neiva-silva.pdf.

Paludo, S. S., \& Koller, S. H. (2008). Toda criança tem família: criança em situação de rua também. Psicologia e Sociedade, 20(1), 42-52. Recuperado em 26 set 2008, de http://www.scielo.br/scielo.php?pid=S0102$-71822008000100005 \&$ script=sci_arttext
Ramalho, J. V. (2008). Crianças em situação de abrigamento que possuem vínculos familiares: busca de significados. Dissertação de Mestrado em Psicologia, Universidade Católica de Pernambuco, Recife. Recuperado em 04 dez 2008, de http://www.unicap. br/tede//tde_busca/arquivo.php?codArquivo=241

Retondo, M. F. N. G. (2000). Manual prático de avaliação do http (casa-árvore-pessoa) e família. São Paulo: Casa do Psicólogo.

Rocha, Z. A. B. (1970). Investigação dinâmica da mente infantil. Petrópolis: Vozes.

Sales, M. A., Matos, M. C., \& Leal, M. C. (2006). Política social, família e juventude: uma questão de direitos $\left(2^{\mathrm{a}}\right.$ ed.). São Paulo: Cortez.

Sarmento, M. J. (2002). Infância, exclusão social e educação como utopia realizável. Educação \& Sociedade, 23(78), 265-283.

Silva, M. F. X., \& Villemor-Amaral, A. E. (2006). A autoestima no CAT-A e HTP: estudo de evidência de validade. Avaliação psicológica, 5(2), 205-215. Recuperado em 06 set. 2008, de http://pepsic.bvsalud.org/scielo. php?pid=S1677-04712006000200010\&script $=$ sci_ arttext

Siqueira, S. D. M., Doro, W. F., \& Santos, E. (2006). O Desenhando a realidade interna. Psic: revista da vetor editora, 4(2),70-76. Recuperado em 06 set 2008, de http://pepsic.bvsalud.org/scielo.php?script=sci_ arttext\&pid=S1676-73142003000200009\&lng=pt\& nrm=iso

Winnicott, D. W. (1984). Consultas terapêuticas em psiquiatria infantil (J. Cunha, Trad.). Rio de Janeiro: Imago.

Psicol. Argum. 2014 jan./mar., 32(76), 69-77 